\title{
Silicon nitride nanotemplate fabrication using inductively coupled plasma etching process
}

Asma Ayari-Kanoun, Abdelatif Jaouad, Abdelkader Souifi, Dominique Drouin, and Jacques Beauvais

Citation: Journal of Vacuum Science \& Technology B, Nanotechnology and Microelectronics: Materials, Processing, Measurement, and Phenomena 29, 051802 (2011); doi: 10.1116/1.3628593

View online: http://dx.doi.org/10.1116/1.3628593

View Table of Contents: http://avs.scitation.org/toc/jvb/29/5

Published by the American Vacuum Society

\section{Articles you may be interested in}

Ultrahigh selective etching of $\mathrm{Si}_{3} N_{4}$ films over $\mathrm{SiO}_{2}$ films for silicon nitride gate spacer etching Journal of Vacuum Science \& Technology B, Nanotechnology and Microelectronics: Materials, Processing, Measurement, and Phenomena 28, 131 (2010); 10.1116/1.3290752

Dry etching characteristics of TiN film using $\mathrm{Ar} / \mathrm{CHF}_{3}, \mathrm{Ar} / \mathrm{Cl}_{2}$, and $\mathrm{Ar} / \mathrm{BCl}_{3}$ gas chemistries in an inductively coupled plasma

Journal of Vacuum Science \& Technology B: Microelectronics and Nanometer Structures Processing, Measurement, and Phenomena 21, 2163 (2016); 10.1116/1.1612517

Control of sidewall slope in silicon vias using $\mathrm{SF}_{6} / \mathrm{O}_{2}$ plasma etching in a conventional reactive ion etching tool Journal of Vacuum Science \& Technology B: Microelectronics and Nanometer Structures Processing, Measurement, and Phenomena 23, 2226 (2005); 10.1116/1.2041654

Contact Hiden Analytical for further details: w www.HidenAnalytical.com E info@hiden.co.uk CLICK TO VIEW our product catalogue

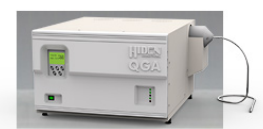

Gas Analysis

- dynamic measurement of reaction gas streams catalysis and thermal analysis - molecular beam studies

dissolved species probes

dissolved spectes proves

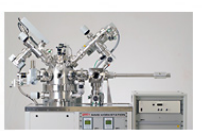

Surface Science

UHVTPD

SIMS elemental imaging - surface mapping

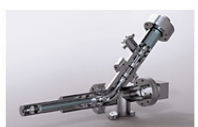

Plasma Diagnostics

, plasma source characterization etch and deposition process reaction , kinetic studies analysis of neutral and radical species

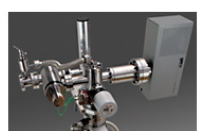

Vacuum Analysis , partial pressure measurement and control of process gases , reactive sputter process control , vacuum diagnostics , vacuum coating process monitoring 


\title{
Silicon nitride nanotemplate fabrication using inductively coupled plasma etching process
}

\author{
Asma Ayari-Kanoun $^{\text {a) }}$ and Abdelatif Jaouad \\ Centre de Recherche en Nanofabrication et en Nanocaractérisation $\left(C R N^{2}\right)$, Université de Sherbrooke, \\ Sherbrooke, Québec, JIK 2R1, Canada \\ Abdelkader Souifi \\ Institut des Nanotechnologies de Lyon (INL), UMR-CNRS 5270, INSA de Lyon, 7 Avenue Jean Capelle, 69621 \\ Villeurbanne Cedex, France \\ Dominique Drouin and Jacques Beauvais \\ Centre de Recherche en Nanofabrication et en Nanocaractérisation $\left(C R N^{2}\right)$, Université de Sherbrooke, \\ Sherbrooke, Québec, J1K 2RI, Canada
}

(Received 20 April 2011; accepted 26 July 2011; published 29 August 2011)

\begin{abstract}
In this work, we have investigated the fabrication of ordered silicon nitride nanohole arrays as part of an overall process aimed at producing organized silicon nanocrystals. The authors have demonstrated that it is possible to use inductively coupled plasma etching systems in order to etch nanometric layers, despite the fact that these systems are designed for deep and fast etching. A stable process is developed for shallow etching of silicon nitride nanoholes. The influence of different plasma etching parameters on silicon nitride nanohole properties is analyzed. $30 \mathrm{~nm}$ deep nanoholes of approximately $30 \mathrm{~nm}$ diameter, near vertical sidewalls and a good control of the selectivity are achieved. The overall process provides a simple and reproducible approach based on shallow inductively coupled plasma etching to obtain high quality nanosized silicon nitride templates. A suitable process for organized arrays of $10 \mathrm{~nm}$ diameter silicon nanocrystals realized by electrochemical etching is shown. (C) 2011 American Vacuum Society.
\end{abstract}

[DOI: $10.1116 / 1.3628593$ ]

\section{INTRODUCTION}

The organization of silicon nanocrystals has been a topic of interest in recent years due to their potential application for future large scale integration of nanoelectronic devices such as single electron transistors (SET) ${ }^{1}$ and nonvolatile memories (NVM). ${ }^{2}$ The fabrication of nanocrystals with excellent control over size, location and spacing remains a key requirement to obtain reproducible properties for these nanoelectronic devices. ${ }^{3,4}$ Many research efforts have been focused on nanocrystal organization using nanopatterned surfaces as templates. Among the approaches studied, the organization of nanocrystals on artificial prestructured surfaces is a promising option. ${ }^{5-7}$ This consists of creating a periodic pattern with high-resolution lithography combined with etching techniques. These prepared surfaces present a periodic regular array which serves as a mask for nanocrystal organization. This type of approach has the advantage of being very precise for nanocrystal localization and can achieve a good resolution providing good control of size, location, density, and spacing between nanocrystals. In our work, this approach was elaborated to fabricate silicon nitride nanohole arrays used as masks for the organization of silicon nanocrystals fabricated by electrochemical etching.

Recently, electrochemical etching became a new alternative compared to other common techniques for silicon nanocrystal fabrication. ${ }^{8-10}$ This technique consists of anodizing

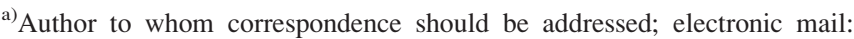
asma.ayari@usherbrooke.ca
}

the surface of monocrystalline silicon wafers by using short single pulses of current in a low concentration of hydrofluoric acid electrolytes and using a current density in a specific anodization regime situated between pore formation and electropolishing. ${ }^{11,12}$ This electrochemical etching has the advantage of being a fast and relatively low-cost technique. Depending on the type of substrates, their doping level and the anodization parameters (time, HF concentration, and current density), high quality silicon nanocystals can be obtained with controlled and reproducible morphologies.

However, to organize these silicon nanocrystals on nanopatterned silicon nitride layers $\left(\mathrm{Si}_{3} \mathrm{~N}_{4}\right)$, the $\mathrm{Si}_{3} \mathrm{~N}_{4}$ nanoholes properties and the silicon $(\mathrm{Si})$ surface quality after template fabrication are crucial for the accomplishment of this fabrication process.

The main possible approaches to fabricate nanometer scale templates are based on direct etching by using focused-ionbeam (FIB) or electron beam lithography (EBL) combined with dry etching process. FIB etching is done directly on the sample leading to template fabrication in a single step. Nevertheless, this technique is far too slow and thus too expensive for template fabrication. In addition, good etch selectivity of $\mathrm{Si}_{3} \mathrm{~N}_{4}$ over silicon is difficult to achieve by using FIB and there is a high likelihood of ion implantation in the substrate. ${ }^{13}$ EBL combined with dry etching process is faster and seems to be more appropriate to obtain good reproducibility and nanohole quality. The reactive ion etching achieves anisotropic etching, but can also induce damage on the silicon surface due to the high levels of ionic bombardment that are 
inherent to this technique. Since the electrochemical etching that governs the nanocrystal formation is highly sensitive to the surface quality, ICP systems are potentially more adapted to this process. The advantage of the ICP etching relative to standard RIE is that the RF platen power controls the energy of the ions bombarding the wafer surface independently from the flux of ions in the plasma. It is well known that ICP systems produce a high density plasma enabling the achievement of high aspect ratio structures with high etch rates, vertical sidewall angle and a good control of selectivity over the resist mask. However, the design of the ICP systems (chamber geometries, $\mathrm{RF}$ source power, gas fluxes, chamber pressure,...) is more adapted to deep etching than thin film etching. ${ }^{14,15}$ For this reason, there are only a few studies in the literature on ICP etching of nanometer scale ultrathin films.

In this work we demonstrate a controllable and reproducible ICP etching of shallow $\mathrm{Si}_{3} \mathrm{~N}_{4}$ nanohole templates, leading to near vertical sidewalls with a good control of the etching rate and the surface quality. A suitable ICP process for fabricating organized silicon nanocrystals by electrochemical etching is developed. In previous work, ${ }^{16}$ we have shown that $30 \mathrm{~nm} \mathrm{Si}_{3} \mathrm{~N}_{4}$ nanoholes are required to obtain a single $10 \mathrm{~nm}$ silicon nanocrystal per each nanohole by electrochemical etching.

In the first section of this paper, we present the required nanohole properties. The second part is then devoted to the description of the fabrication process and the study of the influence of the ICP etching parameters (RF platen and coil powers, chamber pressure) on $\mathrm{Si}_{3} \mathrm{~N}_{4}$ nanohole quality.

\section{REQUIRED NANOHOLE PROPERTIES}

A robust process to realize organized silicon nanocrystals by electrochemical etching on $\mathrm{Si}_{3} \mathrm{~N}_{4}$ nanohole arrays requires specific nanohole properties. Indeed, the etching properties such as selectivity of $\mathrm{Si}_{3} \mathrm{~N}_{4}$ over silicon, anisotropy, and the control of nanoholes size play an important role to insure the success of silicon nanocrystal fabrication. On the one hand, high etching selectivity of $\mathrm{Si}_{3} \mathrm{~N}_{4}$ over silicon is required in order to stop at the $\mathrm{Si}_{3} \mathrm{~N}_{4} / \mathrm{Si}$ interface and to avoid silicon etch. Even minor changes or damage occurring in a few nanometers of the superficial silicon layer has a major impact on electrochemical etching in view of the fact that silicon nanocrystals are formed on the silicon surface. It is then primordial to have a quasi-virgin silicon surface for the success of the process. On the other hand, $\mathrm{Si}_{3} \mathrm{~N}_{4}$ nanohole sidewall shape is a very important parameter considering that electrochemical etching is driven by the electric current which can only pass through the $\mathrm{Si}_{3} \mathrm{~N}_{4}$ openings. Since the current lines will follow the trajectory according to the geometrical shape of nanohole sidewalls, near vertical profiles are necessary to produce a good homogeneity of the electrochemical etching. Nanohole size represents also a key parameter for the nanocrystals formation considering that the applied current during electrochemical etching depends on the exposed silicon surface area. Thereafter, $\mathrm{Si}_{3} \mathrm{~N}_{4}$ nanohole size must be precisely controlled to obtain reproducible results for the size and density of silicon nanocrystals.

\section{NANOHOLE ARRAYS FABRICATION PROCESS}

The main steps of our process are EBL and an inductively coupled plasma etching to fabricate templates in a $\mathrm{Si}_{3} \mathrm{~N}_{4}$ thin film. A layer of about $30 \mathrm{~nm}$ thick $\mathrm{Si}_{3} \mathrm{~N}_{4}$ was deposited using low pressure chemical vapor deposition (LPCVD) on a $p$-doped (100)-oriented silicon substrate with a resistivity of $1-10 \Omega \mathrm{cm}$. The LPCVD process used the reaction of dichlorosilane $\left(\mathrm{SiH}_{2} \mathrm{Cl}_{2}\right)$ and ammonia $\left(\mathrm{NH}_{3}\right)$ with respective flow rates of 30 and 54 standard cubic centimeters per minute $(\mathrm{sccm})$ at a temperature of $800{ }^{\circ} \mathrm{C}$ and a pressure of 200 mTorr. In order to prepattern the surface, a layer of ZEP520 resist diluted in anisole was spin-coated to a thickness of approximately $100 \mathrm{~nm}$ on $\mathrm{Si}_{3} \mathrm{~N}_{4}$ layers. ZEP520 is a positive $e$-beam resist, consisting of copolymers of a-chloromethacrylate and a-methylstyrene that has high resolution, sensitivity and contrast as well as relatively good dry etch resistance. ${ }^{17}$ Samples were then annealed at $180{ }^{\circ} \mathrm{C}$ for a few minutes. EBL was performed by means of a LEO1530 scanning electron microscope externally controlled by a computer equipped with lithography software using the nanometer pattern generation system (NPGS). The electron beam energy was fixed at $20 \mathrm{keV}$ and the beam current was varied from 20 to $30 \mathrm{pA}$. In order to obtain nanoscale holes, a single point exposure scheme was used for each point. In this work, a point dose of $2 \mathrm{fC} /$ point was used to write a field of $200 \mu \mathrm{m} \times 200 \mu \mathrm{m}$. After exposure, the development of the resist was completed using ortho-xylene, rinsed in methyl isobutyl ketone (MIBK) and dried in a nitrogen gas flow. This resist template is used as a mask for plasma etching. The $\mathrm{Si}_{3} \mathrm{~N}_{4}$ holes were etched using STS advanced oxide etch inductively coupled plasma system in a gas mixture of $\mathrm{CF}_{4} / \mathrm{He} / \mathrm{H}_{2} \cdot \mathrm{H}_{2}$ and $\mathrm{He}$ were added to the chemistry of $\mathrm{Si}_{3} \mathrm{~N}_{4}$ plasma etching to improve the selectivity and the anisotropy of the process. ${ }^{18,19}$ The chemistry and plasma etching parameters (pressure, RF coil, and platen powers) of the ICP system were optimized in order to obtain adequate etch rates for shallow nanostructures leading to a better control of the selectivity. Therefore, a gas mixture of $\mathrm{CF}_{4} / \mathrm{He} / \mathrm{H}_{2}$ with respective flow rates of 16/140/14 sccm was used. The quality of $\mathrm{Si}_{3} \mathrm{~N}_{4}$ nanoholes was studied under various plasma conditions for RF coil power varying from 100 to $200 \mathrm{~W}$ RF platen power from 15 to $150 \mathrm{~W}$, and chamber pressure from 2 to 12 mTorr.

After $\mathrm{Si}_{3} \mathrm{~N}_{4}$ etching, the resist was stripped using an oxygen plasma cleaning to remove any residual organics. This latter step is essential and very critical for our process since without proper cleaning, electrochemical etching does not produce repeatable nanocrystals. Generally, organic residuals and contaminations are removed by oxygen plasma cleaning. However, plasma $\mathrm{O}_{2}$ conditions must be well optimized to avoid silicon surface damage. In this work, some samples were electrochemically etched just after oxygen plasma cleaning under different conditions. SEM observation of the $\mathrm{Si}$ surfaces after $\mathrm{O}_{2}$ plasma treatment revealed no obvious change, but the electrochemical etching of silicon failed after oxygen plasma cleaning for power exceeding $100 \mathrm{~W}$ and for durations longer than $7 \mathrm{~min}$. This is probably 
due to the damage of the silicon surface caused by the oxygen plasma cleaning beyond these conditions. Several research groups ${ }^{20,21}$ have studied the effect of plasma processing and it was demonstrated that plasma treatment can cause damage, structural change and defects of the superficial layer as a result of the energetic particle bombardment. This damage increases with increasing power and exposure time. Therefore, in this work we have optimized the cleaning process for a power of $100 \mathrm{~W}$ and a duration of $5 \mathrm{~min}$ to thoroughly clean samples before electrochemical etching without damaging the silicon surface.

\section{RESULTS AND DISCUSSION}

All observations and measurements presented here were conducted by scanning electron microscopy. Two series of samples were used for each type of measurement in order to ensure reproducibility of the results.

Figure 1 shows the etch rates and selectivity for the three materials used in our process $\left(\mathrm{Si}_{3} \mathrm{~N}_{4}, \mathrm{ZEP520}\right.$, and $\left.\mathrm{Si}\right)$ as a function of RF platen power and pressure. The effect of RF platen power at fixed RF coil power of $100 \mathrm{~W}$ and chamber pressure of 4 mTorr is shown in Fig. 1(a). For RF platen power between 15 and $50 \mathrm{~W}$, the etch rate of ZEP520 increases slightly; however, the etch rate of $\mathrm{Si}_{3} \mathrm{~N}_{4}$ increases considerably. Therefore, the selectivity of $\mathrm{Si}_{3} \mathrm{~N}_{4}$ over ZEP520 is increased. For a RF platen power of $50 \mathrm{~W}$, this selectivity exhibits a maximum value greater than 5 . Beyond $50 \mathrm{~W}$, the etch rate of ZEP520 increases much faster whereas the $\mathrm{Si}_{3} \mathrm{~N}_{4}$ etch rate increases much slowly. This involves the reduction of the $\mathrm{Si}_{3} \mathrm{~N}_{4} / \mathrm{ZEP} 520$ selectivity. The strong increase of the ZEP520 etch rate beyond $50 \mathrm{~W}$ can be related to the temperature increase which accompany the increase of the RF platen power. Indeed, it was shown that ZEP520 is very sensitive to temperature. ${ }^{22}$ While for silicon, the etch rate remains slow and almost constant compared to the etch rates of $\mathrm{Si}_{3} \mathrm{~N}_{4}$ and ZEP520. Therefore, the $\mathrm{Si}_{3} \mathrm{~N}_{4} / \mathrm{Si}$ selectivity increases significantly from 1 to 18 when the RF platen power is increased from 15 to $150 \mathrm{~W}$.

The effect of the pressure at fixed RF coil power of 100 $\mathrm{W}$ and RF platen power of $50 \mathrm{~W}$ is shown in Fig. 1(b). The etch rate of $\mathrm{Si}_{3} \mathrm{~N}_{4}$ increases significantly from 2 to $12 \mathrm{mTorr}$; however, the etch rate of ZEP520 deacreases slightly by increasing the pressure. Therefore, the selectivity of $\mathrm{Si}_{3} \mathrm{~N}_{4}$ over ZEP520 increases with pressure. While for silicon, the etch rate remains almost constant by increasing the pressure from 2 to 12 mTorr; consequently, the selectivity of $\mathrm{Si}_{3} \mathrm{~N}_{4}$ over silicon also increases. The variation of selectivities with pressure is as excepted for deep etching. ${ }^{23}$

Finally the obtained values of selectivities as a function of RF platen power and pressure provide an acceptable selectivities for this process considering the low thickness of $\mathrm{Si}_{3} \mathrm{~N}_{4}$ layers to etch.

As shown in Fig. 2, by increasing the RF platen power from 50 to $150 \mathrm{~W}$, the $\mathrm{Si}_{3} \mathrm{~N}_{4}$ nanohole diameter increases and the sidewall angle approaches $90^{\circ}$. Increasing RF platen power enhances the directional ion bombardment, resulting in anisotropic etching. This behavior is as expected for deep
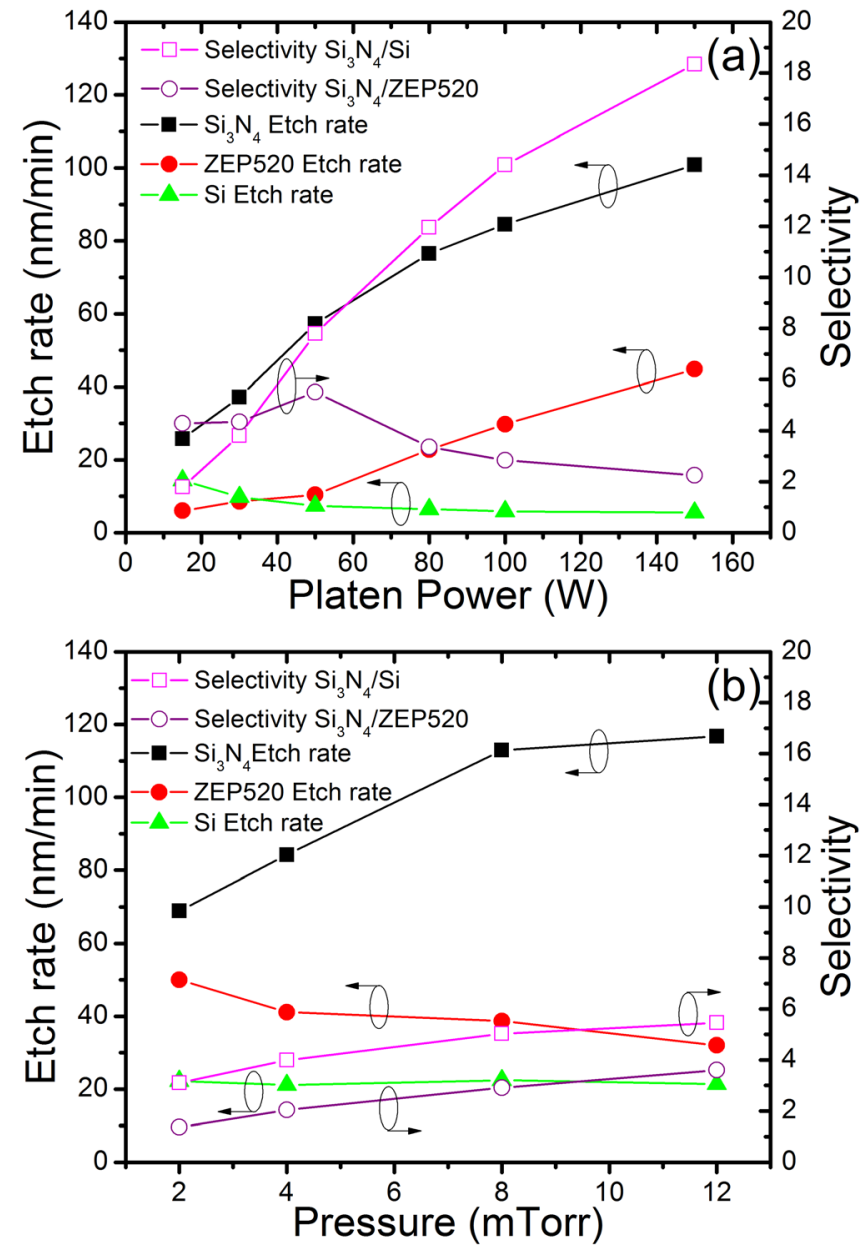

FIG. 1. (Color online) (a) Etch rates and selectivity of $\mathrm{Si}, \mathrm{Si}_{3} \mathrm{~N}_{4}$ and $\mathrm{ZEP} 520$ as a function of RF platen power. (b) The etch rates and selectivity of $\mathrm{Si}$, $\mathrm{Si}_{3} \mathrm{~N}_{4}$ and ZEP520 as a function of pressure.

etching. An example of cross-section SEM images of the profiles of one $\mathrm{Si}_{3} \mathrm{~N}_{4}$ hole fabricated at respectively 50 and $150 \mathrm{~W}$ of RF platen power are shown in the inset in Fig. 2.

The effect of the RF coil power on nanohole diameter and sidewall angle is illustrated in Fig. 3. At fixed RF platen power of $50 \mathrm{~W}$ and chamber pressure of $4 \mathrm{mTorr}, \mathrm{Si}_{3} \mathrm{~N}_{4}$ nanoholes become larger up to a doubling of the diameter with increasing the RF coil power from 100 to $200 \mathrm{~W}$ and sidewall angles approach a straight vertical profile within a few degrees.

As depicted in Fig. 4, the pressure variation between 2 and 12 mTorr does not affect the nanohole diameter on surface at fixed RF coil and platen powers of respectively 100 and $50 \mathrm{~W}$. However, the sidewall angle was found to be more sensitive to pressure variations. Indeed, by increasing the pressure from 2 to $12 \mathrm{mTorr}$, the sidewall angle increases and a nearly vertical sidewall profile can be achieved. This behavior was also observed by other researchers. ${ }^{24}$

With the optimized parameters, we thus precisely control the influence of the plasma conditions on $\mathrm{Si}_{3} \mathrm{~N}_{4}$ nanohole properties (silicon surface quality, verticality, and nanohole size). By choosing proper ICP etching conditions, a good compromise between size, anisotropy and selectivity can be achieved in order to obtain high quality $\mathrm{Si}_{3} \mathrm{~N}_{4}$ nanoholes 


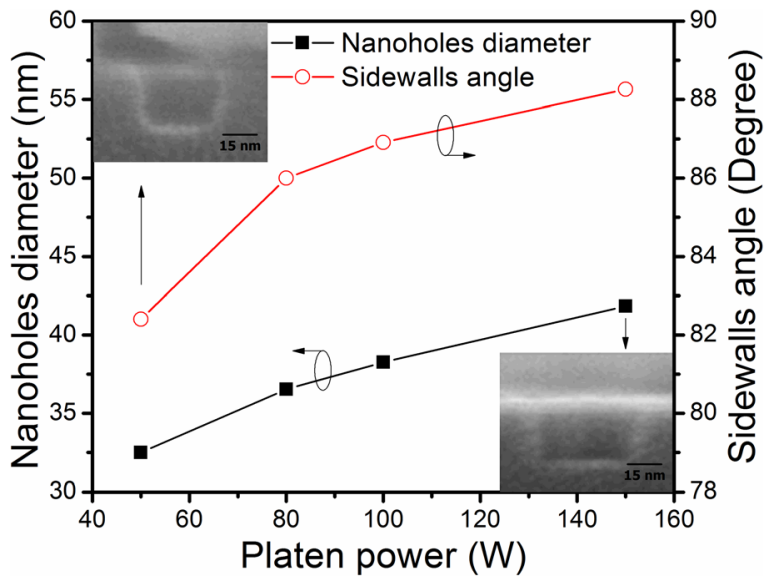

FIG. 2. (Color online) $\mathrm{Si}_{3} \mathrm{~N}_{4}$ nanoholes diameter on surface and sidewalls angle as a function of RF platen power.

well adapted to be used as a mask for silicon nanocrystal organization.

This etching process is limited by the lithography resolution. For ZEP520 electroresist, the resolution can reach 20 nm. ${ }^{25}$ However, in this work, we have optimized the ICP process in order to obtain organized $10 \mathrm{~nm}$ silicon nanocrystal arrays realized by electrochemical etching through $\mathrm{Si}_{3} \mathrm{~N}_{4}$ templates. Since the obtained nanocrystal size and density depends on the nanohole surface area for an electrochemical etching process, a nanohole diameter of $30 \mathrm{~nm}$ is required to obtain a single $10 \mathrm{~nm}$ diameter silicon nanocrystal per each hole. $^{16}$

Figure 5 presents a typical example of organized silicon nanocrystals obtained by using the developed process of ordered $\mathrm{Si}_{3} \mathrm{~N}_{4}$ nanohole arrays. Figure 5(a) shows a SEM image on the surface of nanohole arrays obtained in $\mathrm{Si}_{3} \mathrm{~N}_{4}$ layers by EBL and ICP etching. Holes of $\sim 30 \mathrm{~nm}$ diameter and $200 \mathrm{~nm}$ spacing were obtained in $\mathrm{Si}_{3} \mathrm{~N}_{4}$ layers with a good control of the selectivity of $\mathrm{Si}_{3} \mathrm{~N}_{4}$ over $\mathrm{Si}$ and a reasonably near-vertical profile. Ordered arrays of homogenous silicon nanocrystals localized in these prepatterned $\mathrm{Si}_{3} \mathrm{~N}_{4}$ nanoholes could then be obtained by a short electrochemical

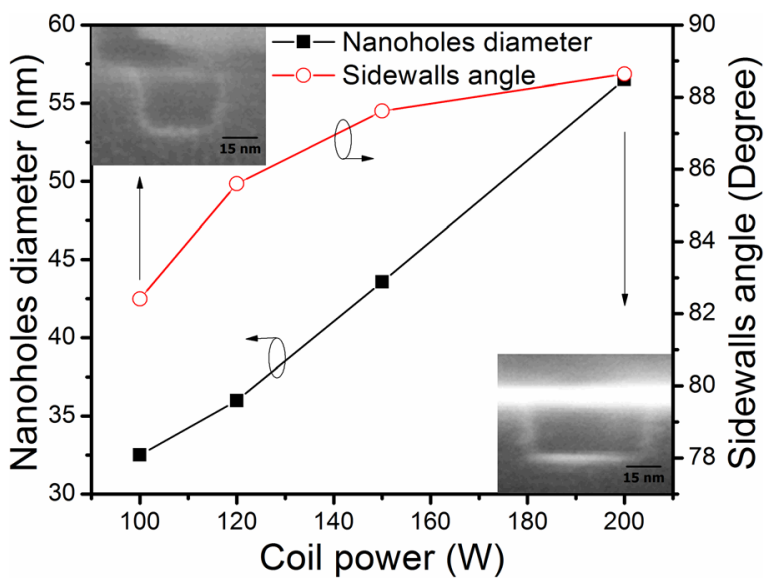

FIG. 3. (Color online) $\mathrm{Si}_{3} \mathrm{~N}_{4}$ nanoholes diameter on surface and sidewalls angle as a function of RF coil power.

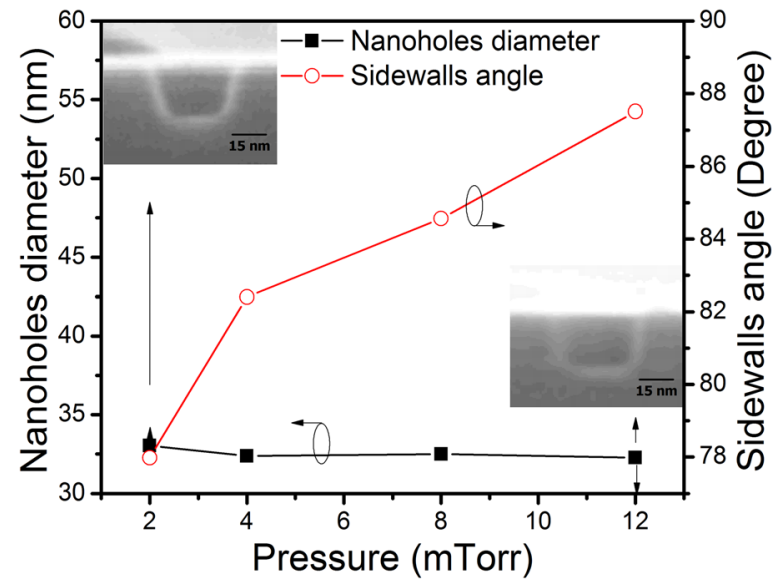

FIG. 4. (Color online) $\mathrm{Si}_{3} \mathrm{~N}_{4}$ nanoholes diameter on surface and sidewalls angle as a function of pressure.

etching current pulse. An example of the obtained nanocrystals with a single silicon nanocrystal per each hole is shown in Fig. 5(b). These nanocrystals have a diameter of approximately $10 \mathrm{~nm}$ and a height of $4 \mathrm{~nm}$ with a conical shape with the same crystallographic orientation as the silicon substrate. ${ }^{16}$

\section{SUMMARY AND CONCLUSIONS}

In summary, we have developed a process for $\mathrm{Si}_{3} \mathrm{~N}_{4}$ nanohole templates fabrication. We have demonstrated that ICP systems which are rather designed for deep and fast

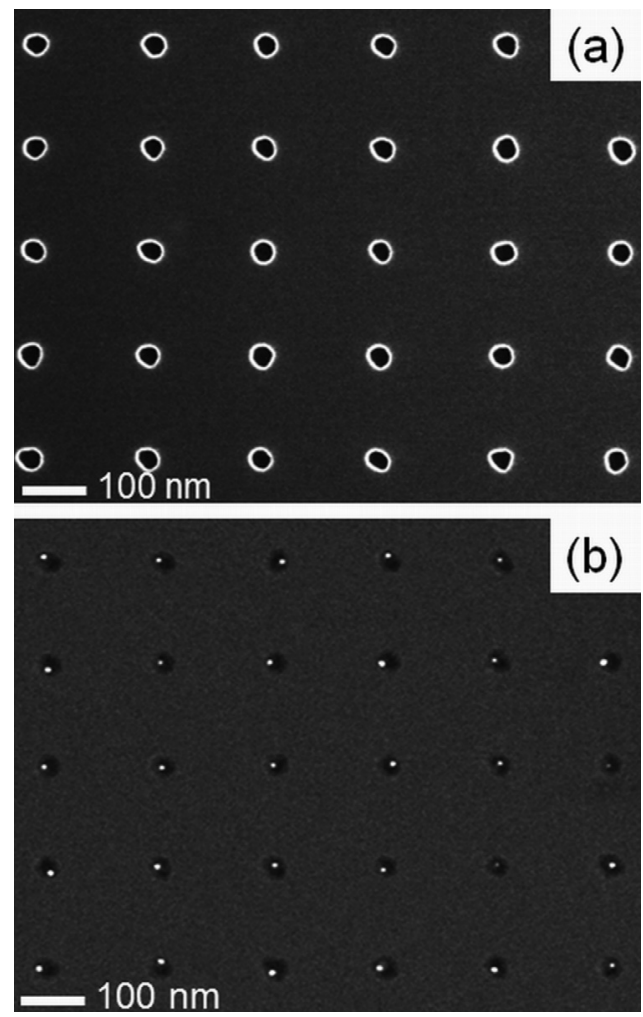

FIG. 5. (a) $\mathrm{Si}_{3} \mathrm{~N}_{4}$ nanoholes array obtained by EBL/ICP. (b) Array of localized $\mathrm{Si}$ nanocrystals after electrochemical etching through $\mathrm{Si}_{3} \mathrm{~N}_{4}$ nanoholes. 
etching can be used for shallow nanostructure etching (about of $30 \mathrm{~nm}$ thick). High quality $\mathrm{Si}_{3} \mathrm{~N}_{4}$ nanohole templates have been successfully demonstrated through the use of EBL and ICP. The influence of ICP parameters (the chamber pressure, the RF coil and the platen powers) on $\mathrm{Si}_{3} \mathrm{~N}_{4}$ nanoholes quality has been discussed. A good compromise between size, anisotropy and selectivity can be achieved to obtain optimal $\mathrm{Si}_{3} \mathrm{~N}_{4}$ nanohole templates compatible with the subsequent fabrication process for the organization of silicon nanocrystals formed by an electrochemical etching technique. These results thus show the high value of ICP system for the fabrication of high resolution of nanoscale patterns in very thin $\mathrm{Si}_{3} \mathrm{~N}_{4}$ films. This process is very promising for many applications and especially for organization of silicon nanocrystal realized by electrochemical etching which can be used in future for large scale fabrication of single electron devices.

${ }^{1}$ A. Nakajima, T. Futatsugi, K. Kosemura, T. Fukano, and N. Yokoyama, Appl. Phys. Lett. 70, 1742 (1997).

${ }^{2}$ S. Tiwari, F. Rhana, H. Hanafi, A. Harstein, E. F. Crabbe, and K. Chan, Appl. Phys. Lett. 68, 1377 (1996).

${ }^{3}$ R. F. Steimle et al., Microelectron. Reliab. 47, 585 (2007).

${ }^{4}$ L. Perniola, B. D Salvo, G. Ghibaudo, A. F. Para, G. Pananakakis, T. Baron, and S. Lombardo, Solid State Electron. 47, 1637 (2003).

${ }^{5}$ P. Kitslaar, M. Strassner, I. Sagnes, E. Bourhis, X. Lafosse, C. Ulysse, C. David, R. Jede, L. Bruchhaus, and J. Gierak, Microelectron. Eng. 83, 811 (2006).

${ }^{6}$ I. Berbezier, A. Karmous, P. D. Szkutnik, A. Ronda, A. Sgarlata, A. Balzarotti, P. Castrucci, M. Scarselli, and M. De Crescenzi, Mater. Sci. Semicond. Process. 9, 812 (2006).

${ }^{7}$ Z. Zhong and G. Bauer, Appl. Phys. Lett. 84, 1922 (2004).
${ }^{8}$ T. Baron, F. Mazen, C. Busseret, A. Souifi, P. Mus, F. Fournel, M. N. Séméria, H. Moriceau, B. Aspard, and P. Gentile, Microelectron. Eng. 61, 511 (2002).

${ }^{9}$ C. Bonafos et al., J. Appl. Phys. 95, 5696 (2004).

${ }^{10}$ T. Inokuma, Y. Wakayama, T. Muramoto, R. Aoki, Y. Kurata, and S. Hasegawa J. Appl. Phys. 83, 2228 (1998).

${ }^{11}$ T. Nychyporuk, V. Lysenko, B. Gautier, and D. Barbier, Appl. Phys. Lett. 86, 213107 (2005).

${ }^{12}$ T. Nychyporuk, V. Lysenko, B. Gautier, and D. Barbier, J. Appl. Phys. 100, 104307 (2006).

${ }^{13}$ A. Karmous, I. Berbezier, and A. Ronda Phys. Rev. B 73, 075323 (2006).

${ }^{14}$ T. Wang, H. C. Chen, H. W. Chiu, Y. S. Lin, G. W. Huang, and S. S. Lu, IEEE Trans. Microwave Theory Tech. 54, 580 (2006).

${ }^{15}$ T. Yamada, H. Yoshikawa, H. Uetsuka, S. Kumaragurubaran, N. Tokuda, and S. I. Shikata, Diamond Relat. Mater. 16, 996 (2007).

${ }^{16}$ A. Ayari-Kanoun, D. Drouin, J. Beauvais, V. Lysenko, T. Nychyporuk, and A. Souifi, Appl. Phys. Lett. 95, 153105 (2009).

${ }^{17}$ L. Merhari, K. E. Gonsalves, Y. Hu, W. He, W. S. Huang, M. Angelopoulos, W. H. Bruenger, C. Dzionk, and M. Torkler, Microelectron. Eng. 63, 391 (2002).

${ }^{18}$ S. Bretoiu, D. Di Mola, E. Fioravanti, and S. Visona, J. Vac. Sci. Technol. B 20, 2085 (2002).

${ }^{19}$ J. L. Lindstrom, G. S. Oehrlein, and W. A. Lanford, J. Electrochem. Soc. 139, 317 (1992).

${ }^{20}$ R. G. Frieser, J. A. Bondur, and E. F. Gorey, J. Electrochem. Soc. 134, 419 (1987).

${ }^{21}$ Y. H. Wang, R. Kumar, X. Zhou, J. S. Pan, and J. W. Chai, Thin Solid Films 473, 132 (2005).

${ }^{22}$ H. Yang, A. Jin, Q. Luo, C. Gu, and Z. Cui, Microelectron. Eng. 84, 1109 (2007).

${ }^{23}$ S. A. McAuley, H. Ashraf, L. Atabo, A. Chambers, S. Hall, J. Hopkins, and G. Nicholls, J. Phys. D: Appl. Phys. 34, 2769 (2001).

${ }^{24}$ M. Guilmain, A. Jaouad, S. Ecoffey, and D. Drouin, Microelectron. Eng. 88, 2505 (2011).

${ }^{25}$ D. J. Resnicka et al., J. Microlithogr. Microfabr., Microsyst. 1, 284 (2002). 